\title{
AN APPROACH FOR DEVELOPMENT AND APPLICATION OF CPSS- EDUCATIONAL ENVIRONMENTS IN BULGARIAN SCHOOL

\author{
Todorka Glushkova ${ }^{1}$, Veneta Tabakova-Komsalova ${ }^{2}$
}

\begin{abstract}
Modern realities in the era of Industry 4.0 and the global Covid-19 pandemic place new challenges to education. It is a fact that classical learning, supported by modern information and communication technologies, provides an effective learning process, but the Covid-19 realities require a rapid transition to distance absentee learning. The use of computer-based training systems and cloud platforms has its advantages, but also problems related to the low level of personalization of the learning process and the adaptability of the learning content to the specific characteristics of each student.

Cyber-physical and social systems (CPSS) largely solve the problems associated with integrating processes and interactions in the virtual world with the dynamically changing conditions of the physical world in which learning occurs. This gives grounds to draw the attention of specialists to the creation of CPSS educational platforms for secondary school. Following this approach, we created a prototype of ь CPSS educational space called BLISS. The results of the test application of this platform in the school environment give us reason to believe that if we put the learner with his/her peculiarities, goals, and interests at the center of such a system, and present him/her in the virtual space through his / her personal assistant, we could significantly increase the interactivity of the learning process and the adaptability of the offered learning content.
\end{abstract}

UDC Classification: 004.8, DOI: https://doi.org/10.12955/pns.v2.148

Keywords: eLearning, interaction, adaptation, CPSS (Cyber-Physical Social System)

\section{Introduction}

Industry 4.0 determines new challenges and tasks, for the solution of which artificial intelligence (AI) played an increasingly important role (Schwab, 2017). The White Paper on Artificial Intelligence of the European Community (WPAI-EU, 2020) sets out the main directions for its development. According to the document, it is necessary to develop skills needed to work in the field of AI and to adapt to the educational systems of all European countries. The report of the CULT (Committee on Culture and Education) committee before the European Parliament on the application of Artificial Intelligence in education (Tuomi, 2020) makes a thorough analysis of the need to train specialists to develop and apply intelligent approaches in various areas of modern business and services. Based on these documents, a strategic document for the development and use of $\mathrm{AI}$ in education and science has been developed in Bulgaria (NSAI, 2020). According to it, given the rapid development of artificial intelligence in recent years and the lag of the formal education system from the needs of the labor market, it is necessary to increase the quality and efficiency of education, to update its content, and to ensure the connection between the education system and the needs of business and society in the age of digital transformation. Based on these strategic documents, two main directions in the application of AI in school education have been identified: a study of the main methods, aspects, and algorithms of AI; use of intelligent educational environments in school practice.

The first direction is related to the need to train specialists who in the future to create and manage processes and systems with AI. This determines the urgent need to experiment with different opportunities for studying AI in school education (Glushkova, 2020).

The second direction requires accelerating the process of developing modern educational platforms with AI to meet the ever-changing characteristics of the environment and meet the education system's growing requirements and expectations.

This article aims to review the existing educational platforms in Bulgaria and consider an approach to creating and using a school intelligent educational platform.

\section{Contemporary trends in the development of educational environments}

The use of the huge opportunities of digital technologies in the educational process is the subject of rapidly growing interest in the conditions of COVID-19. Software companies together with universities develop various educational platforms, which despite their many advantages have a number of problems, mainly related to methodology, pedagogy, and psychology. Of course, various specifications and

\footnotetext{
${ }^{1}$ Faculty of Mathematics and Informatics, Plovdiv University "Paisii Hilendarski”, Plovdiv, Bulgaria, glushkova@uni-plovdiv.bg

${ }^{2}$ Faculty of Mathematics and Informatics, Plovdiv University "Paisii Hilendarski”, Plovdiv, Bulgaria, v.komsalova@uni-plovdiv.bg
} 
standards such as SCORM, IMS, and QTI make it possible to integrate methodological and pedagogical models in the educational platforms and partially solve these problems. The fact is that face-to-face learning has no effective alternative and the use of appropriate educational systems and other ICT tools can support and enrich the learning process as an additional didactic technology. However, the global pandemic has necessitated an urgent process of transferring learning from attendance classroom training to the some internet-based learning systems. This accelerates the processes for creating and applying dynamic, adaptive, intelligent educational platforms to compensate for the lack of physical contact and direct interaction between teachers and students.

\section{Interaction and Adaptation in education}

Interaction and adaptation are key features of any e-learning system, ensuring personalization of training and increasing its effectiveness. In (Lievesley and Yee, 2006) are define three main levels of interactivity - Standard Experience, Personal Experience and Open Experience. Based on this, Nathan Shedroff (Shedroff, 2001) defines six interactive categories connected and related to the main interactive levels. These categories are: Feedback, Control, Productivity, Creativity, Communication, and Adaptation. The first two categories refer to the freedom to choose learning resources and services (tests, lessons, assignments, etc.) according to the student's interests and goals. Productivity, Creativity, and Communication are related to decision-making; the creation of learning resources (such as various simulators, learning games, group work, project training, etc.); and providing effective synchronous and asynchronous learning communication between the various participants in the learning process.

We will consider Adaptation as a key feature of any e-learning system that provides self-tuning and defining functionalities in a way that matches the background knowledge, goals, preferences, habits, cognitive and emotional characteristics and user behavior while working with the system. Two semantically similar concepts are used - Adaptive and Adaptability. Based on these considerations, we can define three upgradeable adaptive levels, the first two of which represent the property of Adaptive and the third one to Adaptability:

- Elementary Adaptive Level (EAL) - this level provides adaptation to the information from the student's user profile, such as the form of education, class profile, etc. The stereotypical approach is used as a result of the collection of educational resources derived from those common to the respective school subject and class. These learning resources use pedagogical methods and techniques traditionally related to the specific group of learners.

- Static Adaptive Level (SAL) builds on the previous level and is aimed mainly at providing learning resources and services suitable for a small group of students with similar characteristics such as level of knowledge, goals, cognitive and emotional characteristics, plans and behavior. The adaptation is realized in advance by the authors of the teaching materials, anticipating the actions and behavior of the typical student from the respective group. The specific learning scenario and the stages for the course of the learning process are determined, which the teachers consider to be suitable for the respective group of students.

- Dynamic Adaptive Level (DAL) is based on the previous two. IP ensures the dynamic interaction between the student and the learning platform during the learning process. Once the learning environment (LMS) has identified an appropriate learning scenario, it starts the learning process as a sequence of actions depending on the student's specific behavior. Based on statistical processing of intermediate results in the course of training and based on stored information about previous training sessions of the same student, the system dynamically adapts, generates new rules and continues the learning process or starts a new one more suitable for the particular student. Typically, intelligent proactive agents are used at this adaptive level to monitor changes in the student's current condition and behavior and to provide a flexible change in the learning process.

\section{Cyber-Physical Social Systems in education}

Cyber-physical systems (CPS) provide integration between the physical and virtual worlds. According to the National Science Foundation (NSF) definition, cyber-physical systems are designed to provide integration of computational processes and algorithms and components that take into account the dynamic changes in the physical environment. 
Learning is a process of interaction between a trainer and a learner. It is, therefore, particularly important to place the user at the center of a CPS system. The unified theory of knowledge proposed by Newell (Newell,1990) explains how intelligent organisms respond flexibly to environmental changes, how they behave and achieve their goals rationally, how they present knowledge and how they learn. Cyberphysical-social space is a fusion of physical space, cyberspace, and social space. The evolution from CPS to CPSS is a long process involving solving various challenges and problems (Yu, 2019). Such systems are already available in areas such as transport, medicine, smart farming and manufacturing, smart cities and houses, etc. The first steps are being taken towards creating CPSS - educational spaces that will take into account the specifics of users in the physical world (e.g., moving a student's wheelchair to the exam hall).

\section{Classification of educational environments in school education}

Learning as a process of interaction between teachers and students goes through different stages in which digital technologies are used to varying degrees. Let's look at the three basic categories: Classical Learning; Computer-Based Training, and e-Learning.

\section{Classical Learning $(C L)$}

Classical Learning is realized through real communication in the physical world between all participants in the learning process - teachers, students, parents, school administration. The interaction between teacher and student is most often of the "One-To-Many" type. Attendance in the classroom has been proven over time, although some problems include the low level of personalization and adaptability of the learning process and materials. These problems are solved by well-established pedagogical theory and practice appropriate didactic methods such as group work, project-based learning, game-based learning, individually-differentiated approaches, and many others. Individual training is organized and conducted for students with exceptional abilities or children with special educational needs. In this case, the training is organized according to individual curricula and teaching materials, and the learning process is personalized and conducted in an inclusive environment. Self-Learning and Lifelong Learning are other forms of classical learning that require differentiation of learning content. As a rule, in the classical forms of education, digital technologies are used as an additional didactic technology to increase the activity of students and the effectiveness of the learning process.

\section{Computer-based Training (CBT)}

CBT is based on the use of ICT and digital technologies in the learning process under the guidance or without the physical presence of teachers. Traditionally, CBT has been used to provide learning resources and services in blended and distance training. The learning process is realized both through pre-prepared learning materials (hypertext documents, audio, video, etc.) and through interactive methods and services such as online discussions and consultations, forums, virtual classrooms, etc. In this training, the curricula for different classes, subjects, and levels of education are pre-established. CBT is significantly more dynamic, interactive, and adaptive than classical training. Modern digital technologies can fully provide this type of training.

In CBT, we can look at two aspects of teacher-student interactions. According to the first of them, the cardinality of the interaction is "One-To-Group" (Figure 1.a). The teacher creates the learning resources according to a pre-set curriculum for the respective group of students. The learning process is aimed at achieving the common goals typical for the group. The adaptability of the learning resources is based on the abstract idea of the teacher for the purposes of the respective stereotypical group. Personalization is low. The interactivity is realized in the categories Feedback, Control, Creativity and Communication. The second aspect defines a "One-To-Persona" interaction (Figure 1.b), which increases the level of personalization of the learning process and adaptability of the learning content. The Persona is a subject representing in the system a fictional student with certain characteristics. The creation of Persona is based on statistical methods, heuristic analysis, and the personal experience of teachers (Lene, 2014). The Persona usually has a name, gender, class, form of education, social competencies, cognitive characteristics, type of emotional intelligence, and more. The adaptation of the learning resources and the learning process is realized on a static level (SAL) by anticipating the actions and behavior of the Person. Different approaches and analyzes are used to determine the knowledge, goals, and desires of the particular student, and based on this, the system joins this student to the Persona with the closest characteristics. The creation of adapted learning resources is a cyclical process. Each stage of this 
process requires assessments and analysis by the pedagogical community in a common environment, e.g., the Integrated Learning Design Environment (ILDE) (Mor, Y., Mogilevski, 2013). This approach increases the adaptation of the learning content and the personalization of the learning process and allows to reach the interactive categories Feedback, Control, Productivity, Creativity, Communication and Adaptation at EAL and SAL levels.

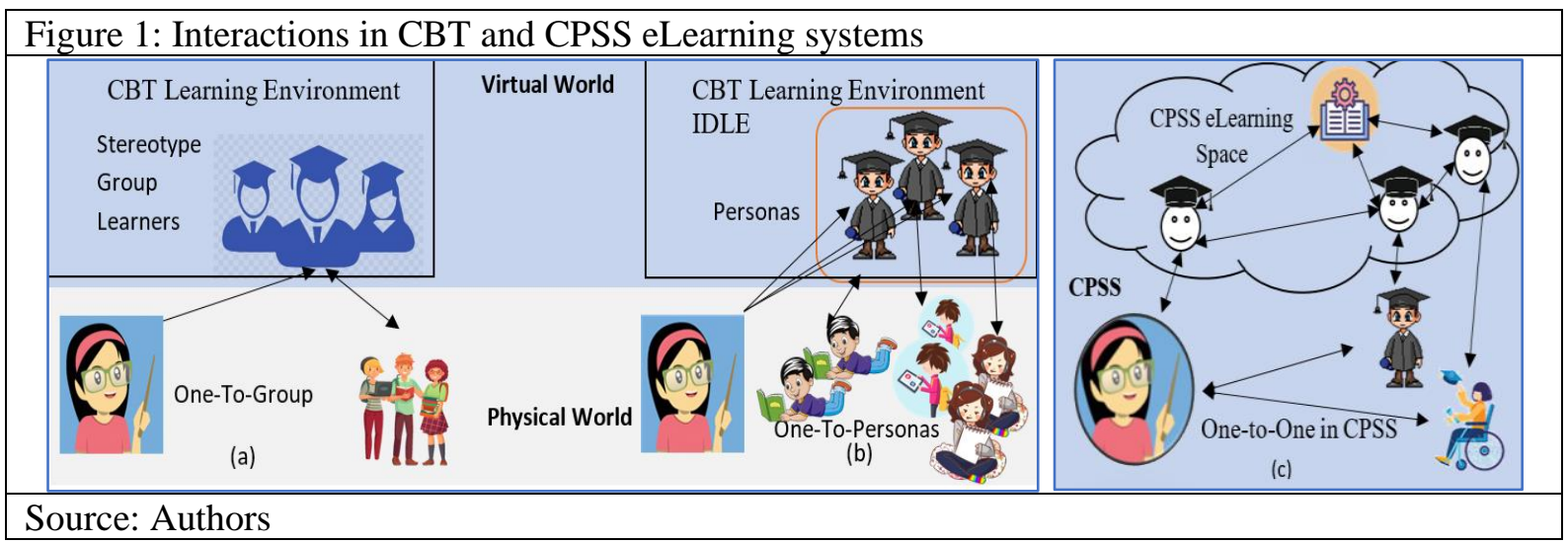

e-Learning

According to (Stoyanov, 2005) e-learning can be considered a qualitatively new learning process, unlimited in time and place, which provides individualization of the learning process and provides appropriate learning resources from any place and at any time at the request of the particular learner. Creating real systems that meet these requirements poses problems and challenges related to adapting the learning content and learning style to each student. This requires the development and implementation of new conceptual solutions, mechanisms for processing and presenting knowledge in dynamically changing conditions. The creation of such educational spaces, based on multi-agent technologies and using AI technologies and algorithms, largely meets these requirements. In this kind of educational space, all participants in the learning process interact through their personal assistants (PA), and the teacher-student interaction becomes "One-To-One". The personalization of the learning process and the adaptability of the learning content are increasing, although the contextual dependence and the dynamic change of the physical environment of the learners are still insufficient.

Cyber-physical and social system (CPSS) is the result of the interaction and merging between physical space, cyberspace and social space. In CPSS, social interactions between different users can be transferred from the physical to the cyberspace, where they can be successfully processed and managed. Thus, users' status, interests, and knowledge develop in the process of social interaction based on certain operations, interactions, and services. (Kang \& al, 2018). In CPS learning spaces, "One-To-One" relationships are reached in CPSS (Figure 1.c). Teachers and students interact personally or through their personal assistants, who are constantly self-learning. The learning content and the learning process are dynamically adapted to the knowledge and specific characteristics of the individual students. These learning spaces realize interactivity and adaptation from all interactive categories and adaptive levels.

\section{Our approach}

In the spring of 2020 in the Bulgarian school, the process of implementing online learning platforms accelerated. According to the Strategy for effective application of information and communication technologies in education and science of the Republic of Bulgaria (2014-2020) of the Ministry of Education and Science, the focus is on organizing virtual classrooms and laboratories and teleconferencing sessions for students. And doctoral students; organization of an e-school and an euniversity; providing platforms for distance training and lesson control, content management, and communication between teachers, parents, and students. For example, in the Plovdiv region in March $2020,75.7 \%$ of schools used an electronic diary, and $31 \%$ used an online learning platform. Within a week, all schools transferred the learning process to a cloud platform of their choice and start use ediary. The G-suit platform proved to be preferred due to the easy setup, time-saving, improving the organization; quality communication; security, and price. All this, along with the ability to use other Gsuit tools such as classroom, calendar, email, etc., established this cloud platform as a preferred distance learning environment to this day. In April 2020, the Ministry of Education and Science purchased and 
provided for use to all schools in the country the cloud platform Microsoft Teams, which is related to the data from the National electronic information system for preschool and school education. An account of the platform was provided for each teacher and student. Microsoft Teams has provided a communication environment and platform for storing and structuring digital learning content. Feedback is provided by creating and grading assignments and online tests. This has partly changed the statistics, as to date, about $39.2 \%$ of schools have transferred education to this platform. Only about $3 \%$ of the schools in Bulgaria use Moodle, Blackboard, or another specialized educational platform. All these systems meet to a greater or lesser extent the requirements of CBT systems. They provide "one-togroup" interactivity between teachers and students; ensure that the interactive levels are reached: Feedback, Control, and Communication, and, to a lesser extent, Productivity and Creativity. Adaptation is at an elementary and static level.

This analysis motivates us to accelerate our work on developing an adaptive e-learning space. A team from the DeLC Laboratory of the Faculty of Mathematics and Informatics of Plovdiv University is working on creating a reference CPSS-based architecture called ViPS (Virtual Physical Space) presented in (Stoyanov, 2018). As a reference architecture, ViPS adapts to a variety of domains, including university and school education. Virtual Educational Space (VES) is the adaptation of ViPS at the University of Plovdiv. It supports various forms of e-learning such as self-directed learning, blended learning, lifelong learning and inclusive learning. We created a prototype of an adapted school learning environment named BLISS and tested it in a real school environment. BLISS is implemented as a multi-agent system and includes two main components. The first component is Personal Assistants (PA) for all participants in the learning process. The second component is a school diary, realized through blockchain technology (Todorov \& al, 2019).

\section{Personal Assistants in BLISS}

The main task of personal assistants is to assist different groups of users in performing their specific functions. We developed the prototypes of the following personal assistants:

- PA_Student - helps students perform their daily duties; informs about upcoming events such as tests, group work, meetings, virtual lessons, consultations, etc. It monitors and reminds the student of the preparation for these events. The assistant is able to prepare analyzes of the results of the learning process.

- PA_Teacher ensures the interaction of teachers with the educational space. Its main function is to assist teachers in the process of analyzing and evaluating the participation, results, and progress of their students. PA_teacher interacts with other personal assistants, thus providing the basic functionalities of the learning environment.

- PA_Principal helps the school principal to effectively manage the school institution. The assistant helps in the process of planning, conducting and controlling the learning process by informing about problems and successes in the course of the learning process.

- PA_Parent is an assistant who interacts with parents and informs them about their child's progress in school. Due to the constant internal communication between the agents and the analysis of the information, the parent can be warned in time for a change in the child's behavior or status, thus having the opportunity to take the necessary actions in the student's interest.

An important part of building the BLISS system is the interactivity between intelligent agents (Krasteva, 2019). Through different types of interactions, they can change their perception of the world, to selfeducate (by machine learning algorithms), and in the next situation to choose another better plan to achieve the goal in the interest of specific users. In addition, BLISS considers the physical world's state, and provides services for users with mobility difficulties, helping them to move around in the physical school environment. According to students and teachers, the most useful functionality of their personal assistants is the reminder of the preliminary preparation for an upcoming event - homework, upcoming lessons, project activities, video conferences, consultations, tests, parent meetings, etc.

One of the interesting and important functionalities of BLISS is the provision of an inclusive environment for students with special educational needs (Toskova, 2021), which provides a differentiated approach to the characteristics of each student through specially designed learning games, learning resources, and services (Petrov \& al, 2020). 
The BLISS prototype is being tested in a real school environment in the Secondary school in Brezovo, Bulgaria. The personal assistant of the student has been developed, in the final stage is the development of the other personal assistants. For security and data protection reasons, prototypes of an electronic diary and processing of documents with factory numbering (diplomas, certificates, etc.) are developed and integrated into the platform. The platform is developed modularly as a distributed infrastructure, and all components are developed using Java-based technologies. The testing was carried out with 360 students (including 18 with special educational needs) and 34 teachers and school staff.

The presented CPSS learning platform ensures the achievement of all interactive categories and adaptive levels. The following Table 1 presents the relationship between the different types of educational environments - classical learning (CL), computer-based training in group (CBT-1), computer-based training with Personas (CBT-2), eLearning systems (eLnSystem) and CPSS learning space (CPSSLSpace), and the interactive and adaptive levels reached in them.

\begin{tabular}{|c|c|c|c|c|c|c|}
\hline \multirow{2}{*}{\multicolumn{4}{|c|}{$\begin{array}{ll}\text { Interactivity Levels } & \text { Adaptive Levels } \\
\end{array}$}} & \multicolumn{2}{|c|}{ Adaptive } & \multirow{2}{*}{$\begin{array}{c}\text { Adaptable } \\
\text { DAL }\end{array}$} \\
\hline & & & & EAL & SAL & \\
\hline \multirow{6}{*}{ 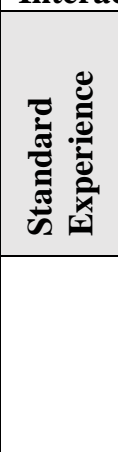 } & \multirow{6}{*}{ 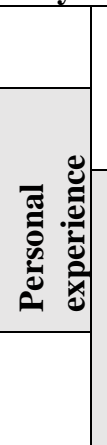 } & \multirow{6}{*}{ 茪 } & Feedback & $\mathrm{CL}$ & $\begin{array}{l}\text { CBT-1 } \\
\text { CBT-2 }\end{array}$ & $\begin{array}{l}\text { eLnSystem } \\
\text { CPSSL Space }\end{array}$ \\
\hline & & & Control & $\mathrm{CL}$ & CBT-1 & $\begin{array}{l}\text { CBT-2, eLnSystem } \\
\text { CPSSL Space }\end{array}$ \\
\hline & & & Creativity & CBT-1 & $\begin{array}{l}\text { CBT-2 } \\
\text { eLnSystem }\end{array}$ & CPSSL Space \\
\hline & & & Productivity & & $\begin{array}{l}\text { CBT-2 } \\
\text { eLnSystem }\end{array}$ & CPSSLSpace \\
\hline & & & Communication & $\begin{array}{l}\text { CL } \\
\text { CBT-1 }\end{array}$ & CBT-2 & $\begin{array}{l}\text { eLnSystem } \\
\text { CPSSLSpace }\end{array}$ \\
\hline & & & Adaptivity & CBT-2 & eLnSystem & CPSSLSpace \\
\hline
\end{tabular}

\section{Conclusion}

The application of CPSS systems in education solves a number of problems related to increasing the level of personalization of the learning process and learning content and the dynamic adaptation to the specific knowledge, characteristics, goals, and interests of the individual student. These spaces have the ability to ensure the achievement of all interactive and adaptive levels through wider use of the capabilities of artificial intelligence. The construction of a context-sensitive space makes it possible to take into account the dynamically changing conditions of the physical world and the learners' environment. This will ensure the processes of the inclusion and support of students from vulnerable groups and students with special educational needs. The development of CPSS educational spaces is an important task through the professional community. An actual task for us is after the development of the main components of BLISS to make a comparison of the test results with world experience in this area. The educational environment BLISS we are developing is still in the prototyping and testing phase, but we already have reason to believe that this approach can provide an appropriate learning environment in which to continue the effective learning of students despite the emergency situation in education imposed by the global pandemic Covid-19.

\section{Acknowledgment}

The results published in this article are part of a study conducted with the financial support of project FP21-FMI-002 "Intelligent Innovative ICT in Research in Mathematics, Informatics and Pedagogy of Education" of the Scientific Fund of Plovdiv University "Paisii Hilendarski" in Bulgaria.

\section{References}

Glushkova, T., Stoyanov, S., Tabakova-Komsalova, V., Grancharova-Hristova, M., Krasteva, I. (2020). An Approach to Teaching Artificial Intelligence in School, Innovative Educational Technologies, Tools and Methods for E-learning Scientific Editor Eugenia Smyrnova-Trybulska "E-learning", 12, Katowice-Cieszyn 2020, pp. 257-267 DOI: 10.34916/el.2020.12.22 Computer Science, Volume 147, 2019, Pages 528-532, ISSN 1877-0509, https://doi.org/10.1016/j.procs.2019.01.233. 
Kang, M., Fan, X., Hua, J., Wang, H., Wang, X., Wang, F. (2018). Managing Traditional Solar Greenhouse With CPSS: A Just-for-Fit Philosophy, IEEE Transactions on Cybernetics, Vol: 48, Issue: 12, 2018, Page(s): 3371 - 3380, DOI: 10.1109/TCYB.2018.2858264

Krasteva, I., Todorov, J., Stoyanov, S. (2019), Intelligent School Education Space, Education and Technologies, Vol. 10, issue 1, 120-126, DOI: http://doi.org/10.26883/2010.191.1489

Lene, N. (2014), Personas. In: Rikke Friis, editor. The Encyclopedia of Human-Computer Interaction. 2nd ed. Denmark: The Interaction Design Foundation, 2014. https:// www.interaction-design.org/encyclopedia/personas.html.

Lievesley, M.A., \& Yee, J. (2006). The role of the interaction designer in an agile software development process. CHIEA'06, pages 1025-1030, https://doi.org/10.1145/1125451.1125647.

Mor, Y., Mogilevsky, O. (2013) Learning Design Studio: Educational Practice as Design Inquiry of Learning. In: EC-TEL 2013; 17-21 September 2013; Paphos. Berlin: Springer; 2013. p. 233-245. https://doi.org/10.1007/978-3-642-40814-4_19

Newell, A. (1990). Unified Theories of Cognition, Harvard University Press, Cambridge, MA, 1990.

National Strategy for the development and use of AI in Bulgaria. (NSAI, 2020). Retrieved March, 10, 2021, from http://www.bas.bg/en/2020/07/13/a-national-strategy-for-the-development-of-artificial-intelligence-in-bulgaria-until-2030was-developed-by-bas/

Petrov, A., Epitropova, A., Stoyanov,S. (2020) Intelligent software agents in help of learning support for autistic students, EDULEARN20 Proceedings, pp. 4622-4628, ISBN: 978-84-09-17979-4, ISSN: 2340-1117, doi: 10.21125/edulearn.2020.1215.

Shedroff, N. (2001). Experience design 1. Indianapolis, Ind: New Riders Pub.

Schwab, K.(2017). The Fourth Industrial Revolution, publ. Crown Business, USA, 192 pages, ISBN-10: 9781524758868, ISBN-13: 978-1524758868, 2017

Stoyanov, S., I. Ganchev, I. Popchev and M. O'Droma (2005). From CBT to eLearning, Information Technologies and Control, No. 4, 2005, Year III, 2-10, ISSN: 1312-2622.

Stoyanov, S., Stoyanova-Doycheva, A., Glushkova, T., Doychev, E. (2018). Virtual Physical Space - an architecture supporting internet of things applications, XX-th International Symposium on Electrical Apparatus and Technologies SIELA 2018, IEEE, 3-6 June, Bourgas. https://doi.org/10.1109/SIELA.2018.8447156

Todorov, J., Krasteva, I., Ivanova V., Doychev, E. (2019). BLISS-A CPSS-like Application for Lifelong Learning, 2019 IEEE International Symposium on Innovations in Intelligent Systems and Applications (INISTA), Sofia, Bulgaria, 2019, pp. 1-5, doi: 10.1109/INISTA.2019.8778363

Toskova, A., Penchev, G. (2021). Intelligent game recommendation system. AIP Conference Proceedings Vol. 2333, Issue 1, (2021); https://doi.org/10.1063/5.0042063

Tuomi, I. (2020), Research for CULT Committee - The use of AI in education, 2020, Retrieved March, 10, 2021, from https://www.europarl.europa.eu/RegData/etudes/BRIE/2020/629222/IPOL_BRI(2020)629222_EN.pdf

WPAI-EU (2020). White Paper on the AI of EU. Retrieved March, 10, 2021, from

https://ec.europa.eu/info/sites/info/files/commission-white-paper-artificial-intelligence-feb2020_bg.pdf 